LEITURA - LINGÜÍSTICA E LITERATURA, n. 31, p. 45-62, jan. 2003-jun. 2003.

\title{
O FUNCIONAMENTO DISCURSIVO DO HUMOR *
}

\section{Fabiana de Oliveira**}

Resumo: Esta pesquisa mobiliza os fundamentos teóricos da Análise do Discurso para descrever e analisar o funcionamento discursivo do humor. O emprego desse quadro teórico se faz necessário na medida em que as piadas revelam um funcionamento repleto de equívocos, falhas e rupturas que contradizem os ideais da consistência, da completude e da transparência no exercício da linguagem. Além disso, as piadas analisadas confirmam o princípio da exterioridade constitutiva do discurso, ao revelarem em seu funcionamento um discurso já-dito em outra instância enunciativa.

Palavras-chave: piada; ruptura; interdiscurso; acontecimento enunciativo; efeito de sentido.

\section{Preliminares}

Neste texto, pretende-se analisar o funcionamento discursivo das piadas, que se revela no cruzamento de um acontecimento com uma memória discursiva, configurando-se como interdiscurso. Para isso, é preciso tecer alguns comentários prévios.

Em meados do século XX, tornou-se bastante difundida a idéia de que a língua é um sistema homogêneo, estável e que tem a função primordial de servir como instrumento de comunicação. Essa concepção acredita que a língua é um sistema completo, autônomo, transparente e sem contradições.

Para analisar o funcionamento discursivo do humor, será preciso partir de outra concepção de língua, já que o fato de a língua ser um sistema não é suficiente para se afirmar algo sobre sua autonomia, completude, transparência e coerência.

* Este texto é resultado de uma adaptação de dois capítulos da dissertação de mestrado A sustentação discursiva do humor defendida em 2000 no

Programa de Pós-Graduação em Letras da Universidade Federal de Alagoas.

*- Doutoranda do Programa de Pós-Graduação em Letras e Lingüística da Universidade Federal de Alagoas. 
É por isso que se utiliza, neste trabalho, os preceitos teóricos da Análise do Discurso (doravante $\mathrm{AD}$ ) que inserem a língua na perspectiva do discurso, destituindo-a, portanto, do seu pretenso caráter homogêneo e estável. Dessa forma, a língua passa a ser compreendida como um elemento de base material, instável, embora regular e com autonomia relativa. Tudo isso, combinado à materialidade do processo sócio-histórico, constitui o lugar da produção dos efeitos de sentido.

$\mathrm{Na} A D$, a exterioridade do discurso tem um papel fundamental, já que é concebida como constitutiva. E isso é decisivo na análise do humor, uma vez que este é um espaço que revela as rupturas que contradizem os princípios de consistência e completude da língua. Segundo Culioli (apud FERREIRA, 1996, p. 43), "[...] deslizamentos, lapsos, mal-entendidos, ambigüidades não são parasitas da comunicação, ou ruídos sobre um fundo informativo claro, mas fazem parte integrante da atividade de linguagem". O efeito humorístico depende desses mal-entendidos, dos equívocos da linguagem.

Segundo a $\mathrm{AD}$, o princípio da exterioridade constitutiva diz que todos os componentes de um discurso são históricos, seu exterior é densamente povoado por outros discursos e, portanto, sua emergência num determinado texto, numa determinada instância, nunca é original, mas já antecedida de muitas ocorrências. Dessa forma, um discurso tem sempre sua origem num outro discurso.

Nesse sentido, este artigo analisa algumas piadas que causam um determinado efeito de sentido a partir da revelação de uma memória discursiva que as perpassa, constituindo-as num novo acontecimento. No entanto, apresenta-se uma proposta de análise que serve de contraponto para a proposta defendida neste texto.

Para Raskin (1987), a noção de script trabalhada na teoria semântica da linguagem pode fornecer explicações para a pesquisa lingüística do humor.' Dessa forma, propõe a teoria semântico-

1 Segundo Raskin, a teoria semântica acredita que o léxico é "organizado de tal forma que cada palavra numa sentença evoca um script" (p.16), entendido como um bloco estruturado e formalizado de informação 
contextual baseada em scripts para a análise lingüística das piadas estabelecendo, então, que esse gênero deve necessariamente apresentar os seguintes componentes:

1. dois scripts diferentes e compatíveis com o texto;

2. a oposição entre esses dois scripts;

3. um gatilho;

4. uma mudança do modo bona-fide de comunicação para o modo não bona-fide;

5. a pretensão de fazer uma piada.

De acordo com esse autor, um texto que tem esses cinco elementos é uma piada em potencial, cabendo à técnica empregada fazer desse gênero um excelente texto piadístico.

O primeiro elemento corresponde, por exemplo, a uma piada que contém os scripts do médico e do amante que sejam revelados no todo ou em parte do texto. Esses dois scripts revelam uma oposição num sentido especial, o que corresponde ao segundo componente, que pode ser uma oposição de situação real e não-real e suas variantes (real atual/real não-atual; possível/impossível; normal/anormal), ou oposições como bem/mal, vida/morte, dinheiro/não-dinheiro, sexo/não-sexo, entre outras. O gatilho é o elemento que vai operar a mudança de um script para outro. A mudança no modo de comunicação diz respeito à passagem de um modo sério para um modo jocoso de comunicação necessário na intelecção de uma piada. Finalmente, a pretensão, quinto componente, é a intenção de fazer rir por meio exclusivo da enunciação desse gênero.

No próximo item será observada a adequação dessa proposta na análise de algumas piadas. Serão analisados especificamente os três

semântica processada. Assim, uma palavra como médico evoca o conceito de um adulto que estudou por vários anos numa escola de medicina, que trabalha diagnosticando doenças e receitando remédios. Os scripts são entidades semânticas formais que têm origem num processo estabilizado da análise semântica de um texto e de seu contexto lingüístico. Portanto, a natureza contextual dessa teoria baseada em script pode ser positivamente ampliada para a pesquisa do humor. É o que Raskin faz ao formular a teoria semântica do humor baseada em scripts. 
primeiros componentes, visto que a mudança do modo de comunicação e a intenção são requisitos ligados à situação comunicativa.

Análise dos Dados

O corpus deste trabalho é composto por onze piadas selecionadas em diferentes sites da internet pela facilidade no acesso, diversidade e grande número de dados. Nenhuma piada analisada tem autor conhecido, mas todas são conhecidas, repetidas e guardadas pela sociedade: fazem parte, portanto, do domínio público. Apesar de versar sobre variados temas, a maior parte foi selecionada dentro do tema da sexualidade com o objetivo de mostrar como o discurso da sexualidade é atravessado por outros discursos.

Por empregar a metodologia qualitativa, este estudo não se preocupou em quantificar os dados, uma vez que os números não são decisivos para esta análise. Assim, foram selecionadas as piadas que comprovam o fenômeno do intercruzamento de discursos.

O material para análise é uma espécie de humor que se forma necessariamente com palavras e frases. Ela não se constrói apenas com gestos ou com desenhos, mas com sinais lingüísticos. Esse gênero pode realizar-se nas modalidades oral e escrita e possui uma forma de apresentação que guarda suas especificidades ${ }^{2}$. É uma unidade lingüística concreta, dotada de propriedades que a relacionam intimamente com o riso, tomada pelos usuários da língua, em situação de interação, com função comunicativa definida.

\section{PIADA 1}

Nassib decidiu ser generoso. Quando saía da boate, ele colocou alguma coisa no bolso do porteiro:

- Isto é para beber um whisky.

o porteiro olha espantado em direção ao bolso. Havia duas pedras de gelo.

2 A piada geralmente se apresenta em forma de uma narrativa curta com conteúdo picante, surpreendente e notadamente risível. Os dados utilizados neste artigo revelam variadas formas de apresentação que vão desde diálogos longos e curtos, comentários, até enunciados em forma de provérbios. 
De acordo com a proposta de Raskin (1987), essa piada aciona dois scripts no texto: o script de um cidadão turco ou árabe, acionado pelo nome Nassib, e o script de porteiro.

$O$ primeiro inicia o texto com a informação de que a personagem de nome Nassib (nome de origem turca e que evoca a imagem dos turcos como hábeis comerciantes, indivíduos interesseiros e altamente comprometidos com o dinheiro), contrariando a sua índole, decide ser generoso. O item lexical "porteiro" aciona o segundo script (indivíduo do sexo masculino que trabalha na portaria de edifícios residenciais e comerciais, recepcionando as pessoas convidadas e evitando a entrada das não desejadas e que, eventualmente, recebe gorjetas dos mais generosos), aparecendo ainda no primeiro enunciado.

Ainda, podem-se apontar esses dois scripts como opostos, no sentido de ter dinheiro $\mathrm{x}$ não ter dinheiro. Mas, essa oposição não é marcante, a ponto de se afirmar que é um componente determinante na piada. Além disso, definitivamente não é possível dizer que há uma mudança de um script para outro através de um gatilho. A piada 1 não revela a passagem do script do turco para o porteiro, mas mostra que os dois scripts estão postos no mesmo plano no texto.

Identifica-se o enunciado "Isto é para beber um whisky" como o gatilho da piada 1. Não no sentido de operar a passagem de um script a outro diferente, mas como o elemento que garante a existência do enunciado "Havia duas pedras de gelo". A ambigüidade do pronome demonstrativo "isto" pode remeter para sentidos disponíveis como dinheiro, gelo ou até mesmo petiscos que possam acompanhar o ato de beber um whisky. É ao caráter ambíguo do pronome "isto" que se deve a direção argumentativa ou o desfecho realizado.

Essa breve análise revelou inadequada a aplicação dos pressupostos teóricos de Raskin (1987). Assim como estas piadas, há inúmeras outras, principalmente aquelas de estrutura indireta (não se apresentam em forma de narrativa), que não permitem a aplicação dessa teoria do script como responsável pelo efeito humorístico, conforme os exemplos seguintes: 


\section{PIADA 2}

Um turista brasileiro pega uma rodovia com destino a Madri. Em dúvida, ainda num país vizinho, pergunta a um sujeito num posto de gasolina:

- Esta estrada vai para a Espanha?

- Não sei, mas se for vai fazer muita falta.

\section{PIADA 3}

De acordo com um amigo nosso, qualquer um que conseguir, com 70 anos, fazer o que fazia aos 25 não fazia tanta coisa assim quando era jovem...

Essas piadas exemplificam a impossibilidade de identificar a passagem de um script para outro diferente. Ainda assim, verifica-se, no exemplo 2, a presença do script de turista e até mesmo a alusão a sua imagem. No entanto, não há uma mudança para outro script realizada por meio de um gatilho.

Até a primeira fala da personagem "- Esta estrada vai para a Espanha?", o texto é perfeitamente possível, compreendido por qualquer falante e está sendo construído em uma direção naturalmente esperada pelo leitor/ouvinte, conforme as pistas apresentadas no momento da contextualização (um turista com dúvidas sobre o percurso tomado na viagem).

No entanto, o emprego do verbo "ir", nesse enunciado, possibilita a resposta "Não sei, mas se for vai fazer muita falta", quebrando a expectativa que vem sendo construída ao longo da narrativa e fazendo com que o leitor/ouvinte acione outro sentido para o verbo "ir", compreendendo o texto como uma piada.

O exemplo 3 também não revela essa oposição entre scripts diferentes, nem mesmo é possível identificar um script. Nessa situação, encontram-se muitos exemplos, o que corrobora a conclusão de que os componentes identificados e descritos (pelo menos em relação aos scripts), por Raskin (1987), não precisam necessariamente estar presentes para configurar um texto como uma piada. 
Para este autor, a presença do gatilho, que pode se manifestar na forma de um trocadilho, é mais importante para a produção de uma piada que qualquer outra combinação de fatores. O exemplo mais simples de trocadilho é o emprego de palavras homônimas, polissêmicas, de afirmações falsas, entre outros recursos lingüísticos.

É possível descobrir num script um gatilho em potencial. Dessa maneira, a ambigüidade sintática é menos óbvia que a possibilidade de significados oferecidos por um homônimo, e mais difícil de ser descoberta.

Segundo Raskin (1987), em algumas piadas, o segundo script apresenta-se fortemente sugerido pela situação comunicativa, diferentemente da forma como é comumente descrito. Isso acontece quando o autor desse gênero não encontra uma palavra ou construção ambígua que execute a função de gatilho e, dessa maneira, recorre a uma regra padrão como "Isto me faz lembrar de ..." . Ou seja, quando a piada não tem uma palavra-pivô que exerça a função de um gatilho, uma alusão desencadeada por qualquer construção lingüística ou pelo tratamento dado ao tema em discussão pode desencadear o segundo script. Desse modo, o gatilho mais sofisticado pode ter origem num script que pareça bastante óbvio. Por exemplo, uma piada em forma de diálogo na qual o segundo interlocutor emite um enunciado que faz alusão a uma situação oposta à explícita pelo primeiro interlocutor tem, nessa alusão, a presença do gatilho.

Gil (1991) muda a nomenclatura, mas segue o mesmo posicionamento de Raskin. Denomina tal componente mediador e mostra que ele articula tanto a mudança do campo da primeira proposição para o da segunda quanto a mudança do antecedente para o consequiente. Para a autora, o mediador pode assumir diferentes formas, conforme o mecanismo empregado para confrontar os dois componentes estruturais da piada (antecedente $\mathrm{x}$ conseqüente; 1 proposição $\times 2^{a}$ proposição).

O mediador pode ser produzido por mecanismos lingüísticos que se distribuem nos níveis fonético-fonológicos, morfossintáticos e semânticos. Assim, a rima e a onomatopéia são exemplos de mecanismos fonético-fonológicos que produzem o mediador; a inversão sintática e o arranjo morfossintático de palavras, além da polissemia e da homonímia, no nível semântico, também são recursos 
lingüísticos, entre outros, que revestem o mediador da função de desencadear a oposição entre as proposições.

Este estudo defende a idéia de que o gatilho não é o elemento essencial da piada, tampouco funciona da forma descrita pelos autores citados. Algumas piadas apresentam o gatilho, outras não. Há textos piadísticos que exigem necessariamente a presença de uma expressão ou palavra que estabeleça uma ruptura no nível discursivo. Não é uma ruptura na ordem da coesão, nem na ordem da coerência, mas na ordem do acontecimento.

Segundo Pêcheux (1990, p.19), o acontecimento é o fato que vai gerar enunciados sobre ele. Tais enunciados reorganizam o acontecimento em seu contexto de atualidade e no espaço de memória que ele convoca. De acordo com esse posicionamento, admite-se que a ruptura revela o acontecimento.

A ruptura é o elemento que representa discursivamente o acontecimento; é a formulação discursiva que trabalha um acontecimento e se manifesta através do intercruzamento de proposições com aparência unívoca e/ou equívoca.

As piadas de estrutura indireta são excelentes exemplos desse funcionamento específico da ruptura. Num enunciado piadístico como "Em terra de voyeur cego quem tem uma mão é rei" pode-se observar que não há uma palavra-pivô que funcione como gatilho, operando a mudança de um script para outro, como defende Raskin (1987), ou articulando a mudança de proposições, como acredita Gil (1991).

Nessa piada, o corte no nível discursivo ocorre no modo como o enunciado está organizado, ou melhor, como os seus componentes, que revelam uma memória discursiva anterior à sua produção, são articulados com vistas à criação de um novo enunciado.

Em textos de estrutura indireta como esse, o rompimento é descrito como a articulação de proposições, oriundas de outras memórias discursivas, que transformam uma piada num novo acontecimento. Assim, de um conhecido provérbio originou-se uma criativa piada. A ruptura é o modo como o velho é articulado para a criação do novo. 


\section{PIADA 4}

Duas bichas estavam conversando num bar:

- Sabe que eu tenho em lema?

- Como assim?

- É que eu sou masoquista.

-E daí?

- Daí o meu lema é: bata antes de entrar.

O enunciado destacado acima revela a ruptura e mostra que a presença do interdiscurso é extremamente necessária, nesse caso específico, para a produção do humor.

O enunciado "bata antes de entrar" revela uma memória discursiva produzida em outro acontecimento enunciativo. O agenciamento desse enunciado, de sentido cristalizado em outros contextos, nessa nova situação discursiva, produz o riso. O novo (o lema da bicha masoquista é "bata antes de entrar") é produzido a partir da articulação com o velho (o enunciado "bata antes de entrar" exposto na porta da sala de um diretor escolar, por exemplo) que tem origem num outro momento discursivo.

Pretende-se mostrar que a ruptura é um componente responsável pelo estabelecimento de uma relação específica do texto humorístico. Isso porque piadas de estrutura indireta nem sempre têm gatilho, no sentido de ser aquela marca textual que desencadeia o riso; no entanto, nem por isso perdem o estatuto de piadas.

Notadamente, admite-se a existência de um elemento que revela um corte no nível discursivo. Esse elemento, que pode ser chamado de ruptura, provoca um rompimento na narrativa, de maneira que quebra a direção argumentativa que vem sendo construída, quebra a expectativa criada pelo leitor/ouvinte, mas não desestrutura o texto. A ruptura é um elemento diferente dos elementos que operam no nível da coesão e da coerência. Na verdade, ela rompe uma direção argumentativa, ao mesmo tempo que assegura a outra tomada. Através de palavras-pivô contidas no gatilho, há possibilidades resguardadas que poderão ser acionadas ou não, mas isso só é descoberto no fecho do texto.

Enfatiza-se que o gatilho estabelece uma idéia de rompimento, de quebra e não uma oposição entre o que está dito antes e depois dele 
como defendem Raskin (1987) e Gil (1991). Além disso, a ruptura representa essa possibilidade de agenciar um enunciado, que revela sua origem em outra memória discursiva, para a produção de um novo, que é o texto humorístico.

As piadas que servem de suporte para esta análise mostram a inscrição da memória discursiva como a presença da exterioridade, constituindo-as. É a evidência do outro no discurso do eu. Um exemplo desse funcionamento pode ser observado no exemplo 5, já brevemente analisado.

\section{PIADA 5}

\section{Provérbio da Playboy:}

Em terra de vouyeur cego quem tem uma mão é rei.

A afirmação da existência do outro num lugar que antes não Ihe era previsto pode ser exemplificada pela piada 5 , que remete $\mathrm{O}$ leitor, imediatamente, para um provérbio bastante conhecido "Em terra de cego quem tem olho é rei”, ou seja, esse texto revela um outro discurso, também em forma de provérbio, bastante conhecido e que tem um enunciador diferente do enunciador da piada.

O riso é provocado justamente pela irrupção de um discurso em outro. É essa filiação do enunciador da piada a outro provérbio que determina a interpretação do sentido e provoca o riso.

Parece óbvio que a presença do outro provérbio é uma condição necessária para a produção de um efeito de sentido específico nesse novo texto. Esse é um exemplo de que o sentido é um efeito produzido a partir do agenciamento do presente com a memória de um já-dito em outro lugar.

As piadas selecionadas trabalham com o tema da sexualidade, mas entrecortadas por discursos oriundos de outras áreas como a política, a religião e discursos caracterizadores de determinadas práticas sociais. As próximas análises são realizadas sobre piadas que revelam esse cruzamento de diferentes discursos. 


\title{
DISCURSO POLÍTICO/SOCIAL
}

\author{
PIADA 6
}

Cuecas, lave-as ou deixe-as.

\section{PIADA 7}

Sacando o pênis, o sujeito fala baixinho:

- Calma, garota! Isto é um assédio.

No exemplo 6, observa-se a presença de um discurso político veiculado num momento específico da história político-social do Brasil. Num certo momento da ditadura militar, os militares promoveram uma campanha que criava nos cidadãos brasileiros um sentimento de amor à pátria e mostrava que os movimentos de esquerda denegriam a imagem da pacífica nação. Assim, surgiu o slogan "Brasil, ame-o ou deixe-o".

O texto "Cuecas, lave-as ou deixe-as" consegue acionar o riso a partir da sua inscrição num outro discurso. É esse funcionamento discursivo específico, ou seja, a transgressão do discurso militar, vigente à época, configurando-se como interdiscurso, que provoca o riso.

Isto quer dizer que esse enunciado - "cuecas, lave-as ou deixe-as" - já foi definido histórica e lingüisticamente em outro momento enunciativo e, por isso, comporta-se como um exterior constitutivo do acontecimento presente.

Apesar de o enunciado piadístico ser construído sobre a articulação de um outro discurso, há unidade, há um efeito de homogeneidade. Esse texto é atravessado por vários discursos, podemse encontrar diferentes formações discursivas, mas essa heterogeneidade adquire um efeito de unidade por meio de uma "vocação totalizante do sujeito". "O locutor constrói a unidade a partir da heterogeneidade e é por uma função enunciativa que o faz. De certo modo, a unidade do texto é um efeito discursivo" (Orlandi, 1986, p. 117).

3 Trata-se do slogan de uma propaganda do governo Médici (1969-1974) que podia ser assim traduzido: "apóie o governo militar ou abandone o país". 
A piada 7, "Sacando o pênis, o sujeito fala baixinho: - Calma, garota! Isto é um assédio", é bem mais interessante porque permite observar como o discurso da sexualidade pode ser atravessado por um outro discurso que revela uma prática social, como o assalto. Não se sabe como esse discurso do assalto foi criado, se a partir de filmes de bang-bang ou do próprio ato de assaltar, entretanto, o enunciado "Isto é um assalto" já está cristalizado, internalizado, de tal forma que qualquer indivíduo diante de uma frase como essa sabe do que se trata.

Segundo Guimarães (1995, p.68), essa relação interdiscursiva mobiliza o conceito de intertextualidade. "A enunciação em um texto se relaciona com a enunciação de outros textos efetivamente realizados, alterando-os, repetindo-os, omitindo-os, interpretando-os." Dessa forma, a interdiscursividade tem uma relação necessária com a intertextualidade e as piadas 6 e 7 são exemplos disso.

\section{DISCURSO RELIGIOSO}

PIADA 8

O homem passa uma cantada na vizinha, que reage:

- Esqueceu que sou casada? O meu marido está viajando. O senhor deveria pelo menos respeitar a mulher do próximo. distante.

- É, mas a Bíblia não diz nada a respeito da mulher do

Essa piada se classifica como sendo de estrutura direta (narrativa com diálogo) e articula o cruzamento entre o discurso religioso e o discurso erótico. A análise mostrará como se dá esse intercruzamento.

O diálogo gira em torno de um assédio, comumente chamado de "cantada", e se passa entre vizinhos. Assim, o homem paquera a vizinha que se encontra sozinha porque o marido está viajando. Ela recusa a cantada, informando essas circunstâncias. Na verdade, se são vizinhos, ele deve conhecer tal fato (pelo menos se a mulher mora com alguém).

O mais interessante nessa piada é o agenciamento de determinadas palavras (próximo $\mathrm{x}$ distante) que estabelecem uma 
relação de sentido e revela um discurso já-dito em outra instância de enunciação e que passa a ter um significado novo nessa piada. Esse jogo ou brincadeira linguiística vai se construindo pouco a pouco, mediante as informações que se acrescentam.

A questão é que os enunciados "Respeitar a mulher do próximo", "Não cobiçar a mulher alheia", "Não desejar a mulher do próximo" são formas variantes do $7^{\circ}$ mandamento do decálogo instituído por Deus em pedras e entregue a Moisés. "Não cobiçarás a mulher do teu próximo" é um enunciado corrente no discurso religioso e atualiza uma memória discursiva. O enunciado "respeitar a mulher do próximo", no exemplo 8, traz à tona esse sentido religioso que foi formulado em outra instância enunciativa. Na piada, o acontecimento discursivo atualiza esse sentido que faz parte do imaginário social, histórico e cultural da sociedade e autoriza a resposta: "- É, mas a Bíblia não diz nada a respeito da mulher do distante." Essa resposta, por sua vez, permite o acionamento de outro sentido para a seqüência "mulher do próximo". No primeiro enunciado, "próximo" significa semelhante, cada pessoa. Na resposta do homem, próximo é aquele que está perto, é uma relação de espaço.

Isso posto, entende-se que a seqüência lingüística "respeitar a mulher do próximo" recupera um sentido que foi formulado em outra instância discursiva. Esse enunciado atualiza no acontecimento presente o discurso bíblico, a história dos dez mandamentos da doutrina católica. Ao proferir "a mulher do distante", o interlocutor carrega uma memória discursiva que serve de sustentação para um sentido novo que tem origem no acontecimento enunciativo, no próprio ato de enunciação. É o acontecimento enunciativo que atualiza a relação de sentido entre "próximo" e "distante".

\section{DISCURSO HISTÓRICO}

\section{PIADA 9}

Assediado pela mulher do imperador, o nobre romano vai, enfim, com ela para a cama. Ao vê-la despida, assusta-se:

\footnotetext{
${ }^{4}$ Exxodo, cap. 20, v.1.
} 


\section{César!}

-Por Júpiter, não posso fazer isso! Dai a César o que é de

PIADA 10

$O$ velho centurião romano chega em casa e implica com o ar satisfeito de sua jovem esposa:

- Tibéria, não vá me dizer que você andou dando a César o que não é de César!

Essas piadas agenciam o intercruzamento do discurso sexual com o discurso histórico. Ambas apresentam uma série de lexemas como "mulher do imperador", "nobre romano", "Júpiter", "centurião romano" (chefe de uma tropa de cem soldados), "Tibéria", que inserem o leitor/ouvinte num contexto bem específico (o do Império Romano) no qual é permitido dizer tudo, desde que faça parte desse contexto.

Nesse sentido, "Dai a César o que é de César", no exemplo 9, e "....dando a César o que não é de César", no exemplo 10, são perfeitamente enunciáveis no contexto criado. A realização dessas sequiências lingüísticas é a questão chave para a produção do riso em cada piada apresentada.

No exemplo 9, o enunciado-chave encontra-se em sua "forma literal", isto é, da forma como é veiculado no discurso histórico: um imperativo seguido de uma afirmação - "Dai a César o que é de César". Nesse texto, tal enunciado é emitido para validar a recusa do envolvimento numa relação extraconjugal, já que a mulher é feia e é a esposa de César. O exemplo 10 apresenta o enunciado em questão com algumas modificações: uma forma nominal que expressa um fato de modo vago e impreciso acompanhado de uma negação - “... você andou dando a César o que não é de César". Nessa piada, o enunciado é ligeiramente alterado para comportar uma suspeita de traição. Em outras palavras: você por acaso deu a César o que não é de César, já que Tibéria é jovem, bela, e feliz, mesmo sendo a esposa de um velho. Nesses enunciados, o verbo "dar" é empregado de forma a destacar o sentido sexual da ação representada pelo verbo.

O enunciado "Dai a César o que é de César" atualiza uma memória discursiva, já que foi formulado em outra instância 
discursiva e, ao mesmo tempo, essa relação de sentido assume um novo significado no acontecimento enunciativo presente, visto que, originalmente, essa sequiência não aponta para o sentido erótico.

Em resumo, não importa se o verbo "dar" é polissêmico ou ambíguo, a questão é que um discurso que constitui o imaginário social, histórico e cultural da sociedade se atualiza na piada, uma vez que já foi definido, histórica e lingüisticamente, em outro momento enunciativo e, dessa forma, comporta-se como um exterior constitutivo do acontecimento presente.

Nas duas piadas, os enunciados "Dai a César o que é de César" e "... andou dando a César o que não é de César" apontam um efeito de memória a partir da qual esses enunciados são tematizados. Ou melhor, o efeito pretendido por ambas só é alcançado através da presença do interdiscurso.

\section{PIADA 11}

A gracinha está preenchendo um formulário de emprego numa agência de relações públicas. Após preencher os itens nome, idade, surge a questão sexo. Pensa um pouco e escreve: três vezes por semana.

De acordo com os pressupostos teóricos da $\mathrm{AD}$, pode-se dizer que é o interdiscurso que revela o discurso preconceituoso contra a mulher. O discurso machista divulga que a beleza feminina não pode estar associada ao talento, à dedicação e ao desempenho profissional da mulher. Para completar a lista da discriminação, só faltou dizer que a "gracinha" candidata ao emprego é loira, já que é bastante conhecido o discurso que faz a associação entre "loira" e "burra", revelado em inúmeras piadas e músicas. O elemento que causa a ruptura na piada é o interdiscurso, isto é, ao revelar o discurso machista que discrimina a mulher, produzido em outro momento enunciativo, permite mais de uma direção argumentativa e desloca os sentidos, fazendo com que o leitor selecione, entre as possíveis direções, a que manifesta a insipiência feminina. Esse processo discursivo que consiste no acionamento da memória discursiva produz efeitos de sentidos e instaura um novo acontecimento enunciativo que é a própria piada. 

exemplo:

Outra manifestação do interdiscurso se dá com o seguinte Nassib decidiu ser generoso. Quando saía da boate, colocou alguma coisa no bolso do porteiro:

- Isto é para beber um Whisky.

O porteiro olha em direção ao bolso. Havia duas pedras de gelo.

Essa piada já foi analisada com o objetivo de mostrar que não há uma mudança de scripts opostos produzindo o efeito humorístico, como defende a teoria semântica do humor (Raskin, 1987). A imagem evocada pelo script do turco (hábeis negociantes, espertos, mesquinhos, interessados apenas no lucro que possa obter em qualquer negociação) é chamada pela $\mathrm{AD}$ de interdiscurso. É a memória discursiva que atravessa o texto, acionando discursos subjacentes, produzidos em outras instâncias enunciativas, mas que é trazido para o acontecimento para provocar efeitos de sentido. O enunciado que inicia a piada "Nassib decidiu ser generoso" já carrega um saber discursivo de que Nassib não é generoso, e que somado à origem do nome "Nassib" vai construindo um percurso discursivo que leva o leitor ao fecho pretendido pela piada.

Deve-se salientar que a equivocidade de sentidos produzida pelo pronome "isto" permite a duplicidade de sentidos, imprescindível para causar o efeito pretendido, mas é o interdiscurso que vai determinar qual sentido terá o estatuto de dominante.

\section{Considerações finais}

É a noção de exterioridade trabalhada pela $\mathrm{AD}$ que mais se adequa à explicitação do fenômeno encontrado nas piadas selecionadas, uma vez que a $\mathrm{AD}$ "vê em todo texto a presença de um outro texto necessariamente excluído mas que o constitui" (ORLANDI, 1994, p. 180).

As piadas analisadas neste trabalho revelam que o efeito humorístico é alcançado por meio da inscrição de uma memória discursiva que atravessa o texto e o constitui num novo acontecimento. A presença dessa exterioridade, também denominada de interdiscurso ou memória discursiva, mostra que a piada teve origem em outra instância enunciativa, que foi definida histórica e 
lingüisticamente em outro momento enunciativo. Essa memória irrompe um discurso em outro, cria um efeito de unidade e comportase como um exterior constitutivo do acontecimento presente. $\mathrm{O}$ princípio da exterioridade constitutiva mostra que a piada funciona como um acontecimento caracterizado social e historicamente, que tem relação com outros textos e com suas condições de produção.

Salienta-se que as piadas podem acionar muitos e diferentes recursos lingüísticos para produzir o efeito humorístico. Vários estudos realizados podem comprovar tal afirmação. O propósito deste trabalho é mostrar mais uma vertente, um aspecto discursivo utilizado para produzir humor. Assim, a presença do interdiscurso é, no corpus analisado, a questão primordial para a produção e a interpretação do riso na piada.

\section{Referências}

BÍBLIA. Português. Bíblia Sagrada. Trad. de João Ferreira de Almeida. Ed. rev. São Paulo: Sociedade Bíblica Trinitariena do Brasil, 1994 / 95.

GIL, Célia Maria Carcagnolo. A linguagem da surpresa: uma proposta para o estudo da piada. Tese (Doutorado em Lingüística). São Paulo: Universidade de São Paulo, 1991

FERREIRA, Maria Cristina Leandro. O estatuto da equivocidade da língua. Estudos da linguagem, Porto Alegre, n.10, p. 39-50, 1996.

GUIMARÃES, Eduardo. Os limites do sentido. São Paulo: Pontes, 1995.

ORLANDI, Eni Pulcinelli. A Análise do Discurso: algumas observações. D.E.L.T.A., v. 2, n. 1, p. 105-126, 1986.

ORLANDI, Eni Pulcinelli. O lugar das sistematicidades linguísticas na análise de discurso. D. E. L. T. A. São Paulo, v. 10, n. 2, 1994.

PÊCHEUX, Michel. O discurso: estrutura ou acontecimento. Trad. Eni Pulcinelli Orlandi. São Paulo: Pontes, 1990. 
RASKIN, Victor. Linguistic Heuristic of Humor: a script-based semantic approach. International Journal of the Sociolog of Language. Berlin/New York/Amesterdam, 65, p.11-25, 1987. 